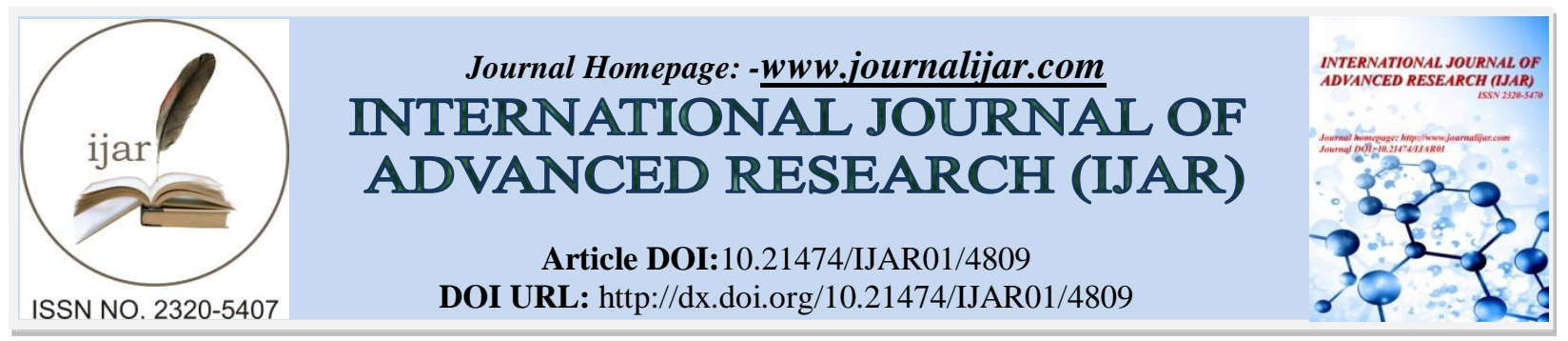

RESEARCH ARTICLE

\title{
ROLE OF CASEIN PHOSPHOPEPTIDE-AMORPHOUS CALCIUM PHOSPHATE (CPP-ACP) IN PREVENTION OF DENTAL CARIES: A REVIEW.
}

\section{Radhey Shyam, Manjunath BC, Adarsh kumar, Ridhi Narang, Mamta Ghanghas and Geeta Rani.}

\section{Manuscript Info}

(..........................

Manuscript History

Received: 10 May 2017

Final Accepted: 12 June 2017

Published: July 2017

Key words:-

CPP-ACP, Dental caries, Caries prevention, Remineralization.

\section{Abstract}

Dental caries is known as a major public health problem worldwide effecting individuals. Effective caries-preventive methods have been developed and refined since the introduction of community water fluoridation in the 1940s. The various topical fluorides which have shown maximum beneficial effect include fluoride varnishes. Among the food groups, dairy products have been recognized as exhibiting anticaries activity i.e milk, milk concentrates and cheeses. Dairy products have been shown to be anticariogenic in animal and human in situ caries models. The bovine milk phosphoprotein, casein, is considered to be largely responsible for this anticariogenic property. The anitcariogenic effect of CPP-ACP has been attributed to the multiphosphoseryl-containing sequences of casein. CPP can stabilize the level of ACP in saliva as it act as reservoir of calcium and stabilizes the level of calcium. We should shift our ways of caries prevention to include products such as CPP-ACP in our prevention schemes for patients through remineralization of enamel and application of minimal invasive approaches in dentistry.

Copy Right, IJAR, 2017,. All rights reserved.

\section{Introduction:-}

Dental caries, otherwise known as tooth decay is one of the most prevalent chronic diseases affecting individual at all ages worldwide and the manifestations of this disease is throughout lifetime and eventually results in increased morbidity. It has been found that $60-70 \%$ of schoolchildren all over the world suffer from dental caries, though the prevalence of dental caries is higher in adult's i.e $99 \% .{ }^{1,2}$

Effective caries-preventive methods have been developed and refined since the introduction of community water fluoridation in the 1940s. Despite the mantra that water fluoridation primarily acts topically and has less effect on pit $\&$ fissures. In India, as community water fluoridation is not feasible so other alternative strategies need to be adopted to prevent this increasing burden of dental caries. ${ }^{3,4}$

The various alternative strategies that have been developed so far for preventing dental caries have proven to be as cariostatic and anticariogenic. The various topical fluorides which have shown maximum beneficial effect include fluoride varnishes. Fluoride varnishes have been developed with the aim of increasing the caries inhibiting properties of fluoride by holding it to tooth surfaces for longer periods of time than other fluoride products. ${ }^{5}$

Despite the use of various professionally applied and individual based topical fluorides, we need to identify the other sources that are cost effective and feasible to the community. One of the readily available sources is the diet that 
every individual consumes for his/her livelihood. Among the food groups, dairy products have been recognized as exhibiting anticaries activity i.e milk, milk concentrates and cheeses. Dairy products have been shown to be anticariogenic in animal and human in situ caries models. The anticariogenic effect of milk products was attributed to a direct chemical effect by cheese components. The bovine milk phosphoprotein, casein, is considered to be largely responsible for this anticariogenic property. ${ }^{6}$

Casein is a phosphoprotein in bovine milk and constitute for approximately $80 \%$ of its total protein content. Casein phosphopeptide (CPP), which contains the amino acid cluster sequence of -Ser(P)-Ser(P)-Ser(P)-Glu-Glu from casein is tasteless, has low antigenicity and can be purified as CPP-ACP nanocomplexes by selective precipitation, ion exchange. ${ }^{7}$

The most commonly used form of CPP-ACP application is via sugar-free sorbitol or xylitol-based chewing gum. Other vehicles include milk, mouth-rinses, lozenges, and dental cream. The CPP-ACP unlike fluoride can be added to sugar-containing foods and therefore have commercial potential as an additive to foods as well as to toothpastes for the control of dental caries. ${ }^{8}$

Hence the present review was undertaken to assess the role of casein phosphopeptide-amorphous calcium phosphate (CPP-ACP) in prevention of dental caries.

\section{Structure Of CPP-ACP:-}

Determination of the dimensions of the CPP-ACP nanocomplex has been extremely difficult. McGann et al ${ }^{9}$ were able to image the calcium phosphate particles using electron microscopy after complex deproteination of casein micelles through the use of hydrazine solutions.

The "closed complex" model of CPP-ACP complex shows that all the charged residues having a significant interaction with the alkaline calcium phosphate core particle, thus rationalizing the observation that shorter CPP analogues bind less calcium phosphate than the full-length CPP. A method for routine preparation of the closed complex CPP-ACP has been developed recently, involving careful titration of calcium ions, phosphate ions and hydroxide ions at $\mathrm{pH} 9.0$ to produce a high molar ratio of Calcium and phosphate ions to CPP. ${ }^{10}$

This result in the loading of the CPP with calcium, phosphate and hydroxide ions in closed complexes that are very stable and can be purified by filtration and dried. RecaldentTM is an alkaline, stable and highly soluble form of CPP-ACP which has been trademarked and has now been marketed as sugar-free gum and mints and in dental professional products (Tooth MousseTM).

\section{Mechanism of Action:-}

Calcium-phosphate reservoir (Prevents demineralization and enhancing re-mineralization):

One of the most challenging actions of CPP-ACP is the formation of Calcium- Phospate reservoir. The anitcariogenic effect of CPP-ACP has been attributed to the multiphosphoseryl-containing sequences of casein. These sequences can be released as casein phosphopeptide after enzymatic digestion of casein. The casein phosphopeptide has a remarkable ability to stabilize calcium phosphate in solution as ACP nanocomplexes, thereby allowing the formation of small CPP-ACP clusters. CPP can stabilize the level of ACP in saliva as it act as reservoir of calcium and stabilizes the level of calcium. ${ }^{11}$

Explanation of this potential has been based on the ability of casein phosphopeptide (CPP) to stabilize calcium phosphate by binding amorphous calcium phosphate (ACP) and thus forming CPP-ACP clusters. These CPP-ACP clusters act as a calcium and phosphate reservoir that attaches itself to dental plaque and tooth surfaces. On acid challenge, the attached CPP-ACP releases calcium and phosphate ions, thus maintaining a supersaturated mineral environment, thereby reducing demineralization and enhancing remineralization. ${ }^{12}$

Furthermore, the nanocomplex of CPP-ACP has been shown to have a synergic effect on fluoridated compounds. This synergic effect must be attributed to the formation of nano-agglomerates of $\mathrm{Ca}, \mathrm{F}$ and $\mathrm{P}$ ions $(\mathrm{CPP}-\mathrm{ACP} / \mathrm{F})$ which results in greater incorporation of fluoride ions into plaque, together with the increase in the concentration of bioavailable $\mathrm{Ca}$ and $\mathrm{P}$ ions. ${ }^{13}$ 


\section{Inhibition of bacterial adhesion:-}

The immunolocalisation studies have revealed that CPP-ACP can be incorporated into supragingival dental plaque by binding to the surfaces of bacterial cells to components of the intercellular plaque matrix and to adsorbed macromolecules on the tooth surface. All these interactions may then lead to the formation of a less cariogenic plaque. Rose (2000) demonstrated that CPP-ACP competes with calcium for plaque calcium binding sites and this will reduce the degree of calcium binding between the pellicle and adhering cells and between the cells. ${ }^{14}$

\section{Indications of CPP-ACP:- ${ }^{15,16,17}$}

1. $\mathrm{CPP}-\mathrm{ACP}$ can be used to remineralize early carious lesions.

2. It has the ability to counteract the action of acids in cases of erosion.

3. It has been proposed that $\mathrm{CPP}-\mathrm{ACP}$ (Tooth-Mousse) has an edge over fluoride tooth paste when it comes to neutralizing acids in the oral cavity.

4. CPP-ACP can also block the dentinal tubules and in turn can reduce the sensitivity.

5. $\mathrm{CPP}-\mathrm{ACP}$ alone or its combination with fluoride can be utilized as a prophylactic agent before the bonding of orthodontic brackets.

6. Used in cases of molar incisor hypomineralization (MIH). This is done for remineralizing hypoplastic molars and remineralization of white spot lesions (enamel opacities and some cases of mild fluorosis).

7. Used in the prevention of dental caries as a cost effective method in high risk population.

8. Used in patients with orthodontic appliances for the purpose of caries prevention and prevention/remineralization of white spot lesions.

\section{Mode of delivery of CPP-ACP:-}

\section{Chewing gum:-}

Sugar free chewing gum containing CPP-ACP paste has shown to promote remineralization of caries in vivo and also it increases calcium concentration in saliva. The addition of $10,18.8$, or $56.4 \mathrm{mg}$ of CPP-ACP to either the sorbitol or xylitol based gums showed $63 \%, 102 \%$, and $152 \%$ of increase in enamel remineralization, respectively. ${ }^{18}$ The CPP-ACP chewing gum is marketed as GC Recaldent ${ }^{\mathrm{TM}}$ (India).

\section{Mouth rinses:-}

When CPP-ACP was delivered in the form of mouth rinses (2\% w/v and $6 \% \mathrm{w} / \mathrm{v}$, respectively), it significantly increased plaque levels, inorganic phosphate levels, and the CPP were immunolocalized to the surfaces of bacterial cells, as well as to the intracellular plaque matrix. ${ }^{19}$

\section{Lozenges:-}

When CPP-ACP was delivered in the form of lozenges, it showed an increase in remineralization of subsurface caries lesions, which is dose dependent and also increased salivary flow rate. Hence, sugar free lozenge may be a suitable vehicle for delivery of $\mathrm{CPP}-\mathrm{ACP} .^{20}$

\section{Topical cream:-}

The twice daily application of 10 fold diluted CPP-ACP paste resulted in preventing dentine demineralization. Enamel microabrasion together with prolonged use of CPP-ACP based paste is useful for treating white spot enamel lesions. $^{21}$

Method of application of topical cream:

It can be applied directly with clean finger onto the teeth, smeared over all surfaces, and left in place to slowly dissolve overnight. Any material that is swallowed is completely safe and will contribute toward dietary calcium.

\section{Dentifrices:-}

The addition of $2 \% \mathrm{CPP}-\mathrm{ACP}$ to the $1100 \mathrm{ppm}$ fluoride dentifrice increase enamel subsurface remineralization by $156 \%$ relative to that produced by $1100 \mathrm{ppm}$ fluoride alone dentifrice and also the incorporation of CPP-ACP into $250-500 \mathrm{ppm} / 900 \mathrm{ppm}$ of fluoride was shown to be effective in increasing enamel remineralization. The increased concentration of calcium, phosphate, and fluoride ions at the tooth surface would drive diffusion into the enamel, producing higher activities of the ions in the subsurface lesion, resulting in higher levels of remineralization and fluoride incorporation into mineral phase. ${ }^{22}$ 


\section{Sprays:-}

Hay and Thomson observed moistening and lubrication action with the CPP and calcium phosphate complex mouth rinse when used as an atomized spray in the mouth. ${ }^{23}$

\section{Energy drinks:-}

Adding CPP-ACP to energy drinks reduces their erosive capacity with no change in flavor when added in proportion of over $0.09 \% \mathrm{CPP}-\mathrm{ACP}$, and it is an important constituent of tooth friendly soft drink. ${ }^{24}$

\section{Discussion:-}

CPP-ACP is a milk product which helps in remineralization and prevents dental caries. Casein phosphorpeptide can deliver amorphous calcium phosphate (ACP) and can also help the ACP to bind with the dental enamel. Casein phosphopeptide can also decrease the count of Strept. Mutans as it has got the ability to integrate in the pellicle. ${ }^{25}$

Caries preventive properties of the CPP-ACP also addressed by Wang $\mathrm{J}$ et al ${ }^{26}$ they clinically evaluated the remineralization potential of casein phosphopeptide amorphous calcium phosphate nanocomplexes for enamel decalcification in orthodontics. After using CPP-ACP for six months they found that CPP-ACP can effectively improve the demineralized enamel lesions during orthodontic treatment, so it has some remineralization potential for enamel decalcification in orthodontics.

One further trial also adds to the weight of evidence supporting the longer-term use of CPP-ACP in patients. In this trial, conducted by authors significant improvements were noted in both groups, but the number of white spot lesions that had completely disappeared after 12 months was significantly greater in the CPP-ACP group (63\% versus $25 \%$, respectively; $\mathrm{p}<0.05){ }^{27}$

Remineralization potential of CPP-ACP paste has been confirmed by many another clinical trial by Bailey DL et $a l,{ }^{28}$ Iijima et al, ${ }^{29}$ Reynolds et al, ${ }^{22}$ Akin M et al. ${ }^{30}$ Mechanism behind this is that CPP-ACP has been shown to localize and stabilize calcium and phosphate ions at the tooth surface in a bioavailable form that can promote remineralization of enamel subsurface lesions in situ, restoring the white opaque appearance of the lesions to translucency.

A study by Akin $\mathrm{M}$ et al $^{30}$ evaluated that use of CPP-ACP can be more beneficial than fluoride rinse for postorthodontic WSL lesions. This in contrast with the study by Llena $\mathrm{C}$ et $a l^{31}$ in which they found that CPP-ACP is not superior to fluoride varnish in prevention of early carious lesions.

Bröchner et al, ${ }^{32}$ Beerens et al, ${ }^{33}$ Aljehani et al, ${ }^{34}$ to investigate caries preventive effects of these products have observed only on carious lesions on smooth surfaces after orthodontic treatment, and their results are generally inconclusive. However, the one study by Altenburger et al ${ }^{35}$ to differentiate between pit-and-fissure WSLs and those on smooth surfaces found that a CPP-ACP formulation produced significantly higher remineralisation than did a toothpaste containing $1450 \mathrm{ppm}$ fluoride.

Llena $\mathrm{C}$ et $a l^{31}$ found little evidence for a substantial effect of the CPP-ACP and fluoride treatments on pit and fissure caries which may be due to difficulty in penetrating deep into the anatomy of these lesions. This support the recommendation by Beauchamp et $a l^{36}$ that caries prevention on the occlusal surface is best approached through the early preventive use of fissure sealants where possible.

\section{Problems with current evidence:-}

Topical CPP-ACP paste has been shown to be an effective remineralising agent for the treatment of natural and post-orthodontic WSLs however, the current evidence regarding its clinical efficacy is highly conflicting as shown by Beerens MW et al, ${ }^{33}$ Andersson A et al. ${ }^{27}$

The combined use of CPP-ACP and fluoride has been reported to exhibit a synergistic anticariogenic effect. This synergistic phenomenon has been attributed to the formation of fluoridated CPP-ACFP complexes which co-localise bioavailable calcium, phosphate and fluoride species on the tooth surfacehowever other researchers argue that insufficient evidence currently exists to confirm this co-adjuvant effect. ${ }^{37,38}$ 
The remarkable discrepancies in the literature regarding the clinical relevance of CPP-ACP have been attributed to variations in study-design, duration of clinical trials, method of application, differences in the activity and severity of lesions, and the possible pathological dissimilarities between orthodontic and non-orthodontic WSLs. The development of CPP-ACP technology is relatively recent and it is currently acknowledged that further clinical studies are required before definitive recommendations for its use can be made.

\section{Conclusion:-}

Based on the previous literature and the proven efficacy of CPP-ACP products through clinical and laboratory studies, it seems that we should shift our ways of caries prevention to include products such as CPP-ACP in our prevention schemes for patients through remineralization of enamel and application of minimal invasive approaches in dentistry.

\section{References:-}

1. Petersen PE. The World Oral Health Report: Continuous improvement of oral health in the 21st century--the approach of the WHO Global Oral Health Programme. Community Dent Oral Epidemiol. 2003;31:23-4.

2. Vos T, Flaxman AD, Naghavi M, Lozano R, Michaud C, Ezzati M et al. Years lived with disability (YLDs) for 1160 sequelae of 289 diseases and injuries 1990-2010: a systematic analysis for the Global Burden of Disease Study 2010. Lancet. 2012 Dec 15;380(9859):2163-96.

3. Groeneveld A, van Eck AAJM, Backer Dirks O. Fluoride in caries prevention: is the effect pre- or posteruptive? J Dent Res 1990;69(751-5):820-23.

4. Singh KA, Spencer AJ. Relative effects of pre- and post-eruption water fluoride on caries experience by surface type of permanent first molars. Community Dent Oral Epidemiol. 2004;32(6):435-46.

5. Rozier RG. Effectiveness of Methods Used by Dental Professionals for the Primary Prevention of Dental Caries. J Dent Edu 2001;65(10):1063-72.

6. Reema SD, Lahiri PK, Roy SS. Review of calcium phosphopeptide- amorphous calcium phosphate. Chinese J Dent Res 2014;17(1):7-14.

7. Morgan MV, Adams GG, Bailey DL, Tsao CE, Fischman SL, Reynolds EC. The anticariogenic effect of sugarfree gum containing CPP-ACP nanocomplexes on approximal caries determined using digital bitewing radiography. Caries Res. 2008;42(3):171-84.

8. Reynolds EC. Anticariogenic complexes of amorphous calcium phosphate stabilized by casein phosphopeptides: a review. Spec Care Dentist. 1998;18(1):8-16.

9. McGann TC, Kearney RD, Buchheim W, Posner AS, Betts F, Blumenthal NC. Amorphous calcium phosphate in casein micelles of bovine milk. Calcif Tissue Int. 1983;35(6):821-3.

10. Reynolds EC. Remineralization of enamel subsurface lesions by casein phosphopeptide-stabilized calcium phosphate solutions. J Dent Res 1997;76(9):1587-95.

11. Vashisht R, Kumar A, Indira R, Srinivasan M R, Ramachandran S. Remineralization of early enamel lesions using casein phosphopeptide amorphous calcium Phosphate: An ex-vivo study. ContempClin Dent. 2010;1(4):210-13.

12. Nair AS , Kumar RK, Philip ST, Ahameed SS, Punnathara S, Peter J. A Comparative Analysis of Caries Inhibitory Effect of Remineralizing Agents on Human Enamel Treated With Er:YAG Laser: An In-vitro Atomic Emission Spectrometry Analysis. J Clinical Diag Res 2016;10(12):10-3.

13. Cochrane NJ, Cai F, Huq NL, Burrow MF, Reynolds EC. New approaches to enhanced remineralization of tooth enamel. J Dent Res 2010;89:1187-97.

14. Gupta R, Prakash V. CPP-ACP Complex as a New Adjunctive Agent for Remineralisation: A Review. Oral Health Prev Dent 2011;9:151-65.

15. Piekarz C, Ranjitkar S, Hunt D, McIntyre J. An in vitro assessment of the role of tooth mousse in preventing wine erosion. Aust Dent J 2008;53(1):22-5.

16. Al-Batayneh Ola B. The clinical applications of tooth mousse and other $\mathrm{CPP}-\mathrm{ACP}$ products in caries prevention: evidence Based recommendations. Smile Dent J 2009;4(1):8-12.

17. Tabrizi Anis, Cakirer Banu. A comparative evaluation of casein phosphopeptide-amorphous calcium phosphate and fluoride on the shear bond strength of orthodontic brackets. Eur J Orthod 2011;33(1):282-7.

18. Shen P, Cai F, Nowicki A, Vincent J, Reynolds EC. Remineralization of enamel subsurface lesions by sugar free chewing gum containing casein phophopeptide-amorphous calcium phosphate. J Dent Res 2001;80(12):2066-70. 
19. Reynolds EC, Cai F, Shen P, Walker GD. Retention in plaque and remineralization of enamel lesions by various forms of calcium in a mouthrinse or sugar-free chewing gum. J Dent Res. 2003;82(3):206-11

20. Cai F, Shen P, Morgan MV, Reynolds EC. Remineralization of enamel subsurface lesions in situ by sugar-free lozenges containing casein phosphopeptide-amorphous calcium phosphate. Aust Dent J 2003;48(4):240-3.

21. Oshiro M, Yamaguchi K, Takamizawa T, Inage H, Watanabe T, Irokawa A, et al. Effect of CPP-ACP paste on tooth mineralization: an FE-SEM study. J Oral Sci 2007;49(2):115-20.

22. Reynolds EC, Cai F, Cochrane NJ, Shen P, Walker GD, Morgan MV, et al. Fluoride and casein phosphopeptide-amorphous calcium phosphate. J Dent Res 2008;87(4):344-8.

23. Hay KD, Thomson WM. A clinical trial of the anticaries efficacy of casein derivatives complexed with calcium phosphate in patients with salivary gland dysfunction. Oral Surg Oral Med Oral Pathol Oral RadiolEndod. 2002;93(3):271-5.

24. Kolahi J, Fazilati M, Kadivar M. Towards tooth friendly soft drinks. Med Hypotheses 2009;73(4):524-5.

25. Schupbach P, Neeser JR, Golliard M, Rouvet M, Guggenheim B. Incorporation of caseinoglycomacropeptide and caseinphosphopeptide into the salivary pellicle inhibits adherence of mutans streptococci. J Dent Res 1996;75(10):1779-88.

26. Wang J, Yan Y, Xiu-jing W. Clinical evaluation of remineralization potential of casein phosphopeptide amorphous calcium phosphate nanocomplexes for enamel decalcification in orthodontics. Chin Med J 2012;125(22):4018-21.

27. Andersson A, Sköld-Larsson K, Hallgren A, Petersson LG, Twetman S. Effect of a dental cream containing amorphous cream phosphate complexes on white spot lesion regression assessed by laser fluorescence. Oral Health Prev Dent. 2007;5(3):229-33.

28. Bailey DL, Adams GG, Tsao CE, Hyslop A, Escobar K, Manton DJ, et al. Regression of postorthodontic lesions by a remineralizing cream. J Dent Res. 2009;88:1148-53.

29. Iijima Y, Cai F, Shen P, Walker G, Reynolds C, Reynolds EC. Acid resistance of enamel subsurface lesions remineralized by a sugar-free chewing gum containing casein phosphopeptide-amorphous calcium phosphate. Caries Res 2004;38:551-6.

30. Akin M, Basciftci FA. Can white spot lesions be treated effectively? Angle Orthod. 2012;82(5):770-5.

31. Llena C, Leyda AM, Forner L. CPP-ACP and CPP-ACFP versus fluoride varnish in remineralisation of early caries lesions. A prospective study. Eur J Paediatr Dent. 2015;16(3):181-6.

32. Brochner A, Christensen C, Kristensen B, Tranæus S, Karlsson L, Sonnesen L, Twetman S. Treatment of postorthodontic white spot lesions with casein phosphopeptide-stabilised amorphous calcium phosphate. Clin Oral Investig. 2011;15(3):369-73.

33. Beerens MW, van der Veen MH, van Beek H, ten Cate JM. Effects of casein phosphopeptide amorphous calcium fluoride phosphate paste on white spot lesions and dental plaque after orthodontic treatment: a 3-month follow-up. Eur J Oral Sci. 2010;118(6):610-7.

34. Aljehani A, Yousif MA, Angmar- Månsson B, et al. Longitudinal quantification of incipient carious lesions in postorthodontic patients using a fluorescence method. Eur J Oral Sci 2006;114:430-34.

35. Altenburger MJ, Gmeiner B, Hellwig E, et al. The evaluation of fluorescence changes after application of casein phosphopeptides [CPP] and amorphous calcium phosphate [ACP] on early carious lesions. Am J Dent 2010;23:188-92.

36. Beauchamp J, Caufield PW, Crall JJ, et al. Evidence-based clinical recommendations for the use of pit-andfissure sealants: a report of the American Dental Association Council on Scientific Affairs. J Am Dent Assoc 2009;53:131-47.

37. Reynolds EC. "Casein phosphopeptide-amorphous calcium phosphate: the scientific evidence. Advances Dent Res 2009;21(1):25-9.

38. Li J, Xie X, Wang Y, Yin W, Antoun JS, Farella M, Mei L. Long-term remineralizing effect of casein phosphopeptide-amorphous calcium phosphate (CPP-ACP) on early caries lesions in vivo: a systematic review. J Dent. 2014;42(7):769-77. 